\title{
Mapping the Temples of Cyborgism: \\ Exploring the Numinous Potential of Replicants in Ridley Scott's Blade Runner
}

Michael Paul Oman-Reagan

\section{Roy: "I've done...questionable things." \\ Tyrell: "Also extraordinary things. Revel in your time." \\ Roy: "Nothing the god of biomechanics wouldn't let you in heaven for." 1}

Ridley Scott, et al., Blade Runner

Cyborgs challenge the praxis that has traditionally divided human and machine (and companion/slave, animal/food, creator/creation, etc.). In doing so, they threaten to disrupt "certain dualisms" that Donna Haraway suggests "have been persistent in Western traditions." ${ }^{2}$ Like cyborgs, the replicants of Ridley Scott's Blade Runner are situated outside the human/machine polarity. By threatening binary systems and insisting on an identity of plurality, replicants and cyborgs are granted access to a sanctuary in which they can interface with the numinous place of origin; the place Jenna Tiitsman describes as the chaotic "territory of creation." ${ }^{3}$ The following analysis is a journey of exploration to map the cyborg sanctuaries in that chaotic territory of Tiitsman's "creative becoming."3

This expedition will explore the web of shared conversation between discourse in three regions: investigation into human reactions to robot humanness, relational ordering of religious experience, and the capacity of 
cyborgs to access the numinous. At the intersection of these cognitive spaces emergent from the "territory of creation"3 are conceptual-crossroads where cyborgs mediate access to the supernatural. To situate these emergent conceptual-crossroads within more familiar cognitive spaces with supernatural access, I will refer to them as the temples of cyborgism.

\section{Theoretical Framework: Cognitive Spaces \& Numinous Geography}

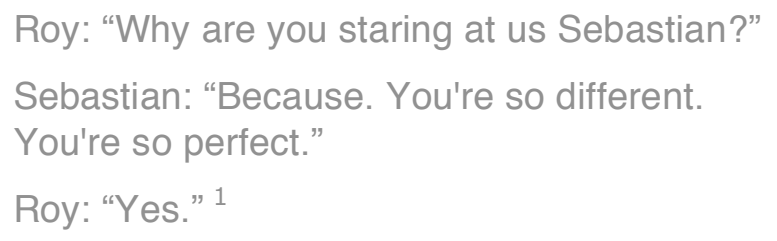

Ridley Scott, et al., Blade Runner

Just as J.F. Sebastian, a genetic designer in the Blade Runner universe, identifies the ostensibly non-human replicants as "perfect," Japanese roboticist Masahiro Mori has amended his map of the uncanny valley to include a "human ideal" which he describes as "more attractive than human beings" and "beyond the worries of life." 4 As an example of this quintessence of humanness, Mori cites the artistic expression (sculptural) of the human ideal (the Buddha). ${ }^{4}$ In a related ordering of humanness, Anthropologist Karl W. Luckert has defined religious experience as a relational response to "greater-than-human configurations of reality." ${ }^{5}$

In this investigation, I will incorporate Mori's expanded map of the uncanny valley along with Luckert's model for ordering religious experience into a hybrid 
framework through which to assess replicant potential as mediator of the numinous; a cyborg qua god/shaman/deity. Within this framework, I will further map the temples of cyborgism by engaging with Donna Haraway's discourse on the dualism-challenging-replicant which she advances as embodying the creative potential of "cyborg culture's fear, love and confusion" ${ }^{2}$ and David Harvey's discourse on the "disappointing" ${ }^{\text {"6 }}$ simulacra-replicant which he argues can neither surpass nor differentiate itself from the 'original. ${ }^{6}$

\section{More Human Than Human: The Cyborg Aura}

\section{Tyrell: "...here at Tyrell. More human than}

human is our motto."1

\section{Ridley Scott, et al., Blade Runner}

In response to Views of the Uncanny Valley (a workshop at the 2005 Institute of Electrical and Electronics Engineers/Robotics and Automation Society International Conference on Humanoid Robots) Masahiro Mori amended his 1970 map of the uncanny valley in a brief article entitled On Uncanny Valley. ${ }^{4}$ In Mori's original graph of familiarity vs. appearance (human likeness) "living human beings" were placed on the upper right hand side of the uncanny valley to express the most "human likeness" and "familiarity" while an industrial robot (of the type used to manufacture cars) was placed on the lower left of the graph, closest to the axis, to indicate the least "human likeness" and "familiarity."7 
Mori's On Uncanny Valley ${ }^{4}$ proposes a "something more attractive and amiable than human beings in the further right-hand side of the valley." ${ }^{4}$ Mori says this "something" is "the face of a Buddhist statue as the artistic expression of the human ideal." His placement of this "artistic expression of the human ideal $^{\prime 4}$ on the far right-hand side of the graph (Figure 1) indicates that it possesses more human likeness and familiarity than his previous apex of humanness; the "healthy person."

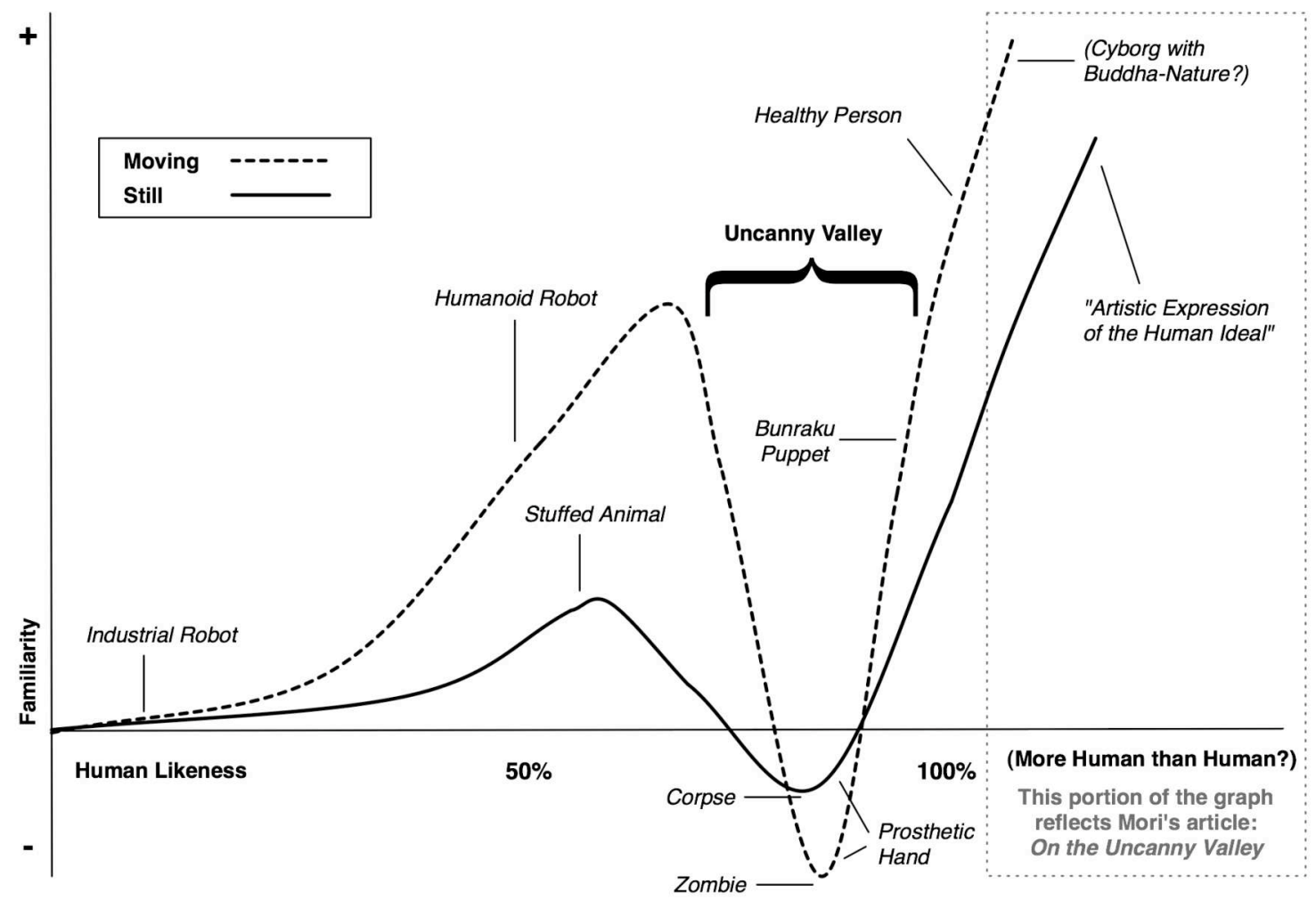

Figure 1: The Uncanny Valley. This figure is based on Mori's original 1970 article on the uncanny valley but has been augmented to include the ideas put forward in his 2005 article On the Uncanny Valley; the inclusion of the "artistic expression of the human ideal" in the "further right hand side of the valley". The questions posed in parentheses are my own. (After Karl F. MacDorman and Takashi Minato's simplified figure from their English translation of Mori, M., Bukimi No Tani [the Un-Canny Valley]. Energy, 1970. Volume 7: p. pp.33-35. and Mori, M., On Uncanny Valley, in IEEE-RAS International Conference on Humanoid Robots. 2005: Tsukuba, Japan.) 
In the 1981 book The Buddha in the Robot, Mori lays the foundations of what would, in 2005, become the addition of "artistic expression of the human ideal" ${ }^{4}$ to the uncanny valley graph:

From the Buddha's viewpoint there is no master-slave relationship between human beings and machines. The two are fused together in an interlocking entity. Man achieves dignity not by subjugating his mechanical inventions, but by recognizing in machines and robots the same Buddha-nature that pervades his own inner self. When he does that, he acquires the ability to design good machines and to operate them for good and proper purposes. In this way harmony between humans beings and machines is achieved..$^{8}$

On Uncanny Valley ${ }^{4}$ suggests an artistic expression in the form of sculpture as the new exemplar of humanness, the moving equivalent of this sculptural representation is a cyborg with the Buddha-nature. At this overlap of Mori's "artistic expression of the human ideal" ${ }^{4}$ and his 1981 argument that robots possess the "Buddha-nature,"8 emerges the first temple of cyborgism; The Temple of The Cyborg Aura. This temple is created by the notion of a mechanical entity made by human beings in the image of the "human ideal" and possessing the same awakened-nature as its creator.

Eldon Tyrell can "gift" the replicants with memories and design them with superhuman mental and physical abilities, but in this temple, the cyborg receives an aura/soul/spirit. With greater than human abilities and the same "Buddhanature that pervades his own inner self" ${ }^{8}$ Mori is constructing an entity to be, as 
Tyrell describes the replicant 'products' of his cybernetics corporation, "more human, than human."1

\title{
Greater Than Human: The Cyborg Ascension
}

\author{
But you see," Pris said, "if you're not human, \\ then it's all different." \\ "That's not true. Even animals -- even eels \\ and gophers and snakes and spiders -- are \\ sacred." \\ Phillip K. Dick, Do Androids Dream of Electric Sheep?
}

In his introduction to volumes 8 and 9 of the 1984 series American Tribal Religions, Anthropologist Karl W. Luckert defines religion as "man's response to so-conceived greater-than-human configurations of reality." ${ }^{5}$ In the introduction to Nordic Religions in the Viking Age, Thomas A. Dubois condenses Luckert's theory on the origins of religious experience into the following synopsis:

\begin{abstract}
All people....and all cultures, divide their experiences of the world into several categories. Elements or experiences that the culture or individual regards as less than human are "handled": controlled, analyzed, conquered, dismissed. Elements or experiences viewed as equal to human are treated as such: shared and communicated with, or competed against. Finally, elements or experiences recognized as greater than human evoke some sort of religious experience, be it mild (fascination), heightened (terror, awe), or extreme (mystic or physical surrender.) ${ }^{10}$
\end{abstract}

Luckert's tripartite division of experiences into "less than human," "equal to human," and "greater than human"10 suggests a series of borders which are 
vulnerable to incursion by the disruptive nature of the cyborg identity I set out to explore. However, like Mori's 1970 graph of "human likeness" and "familiarity" with it's "healthy person" apex, ${ }^{7}$ Luckert's scale provides a useful structural framework from which to explore deviation.

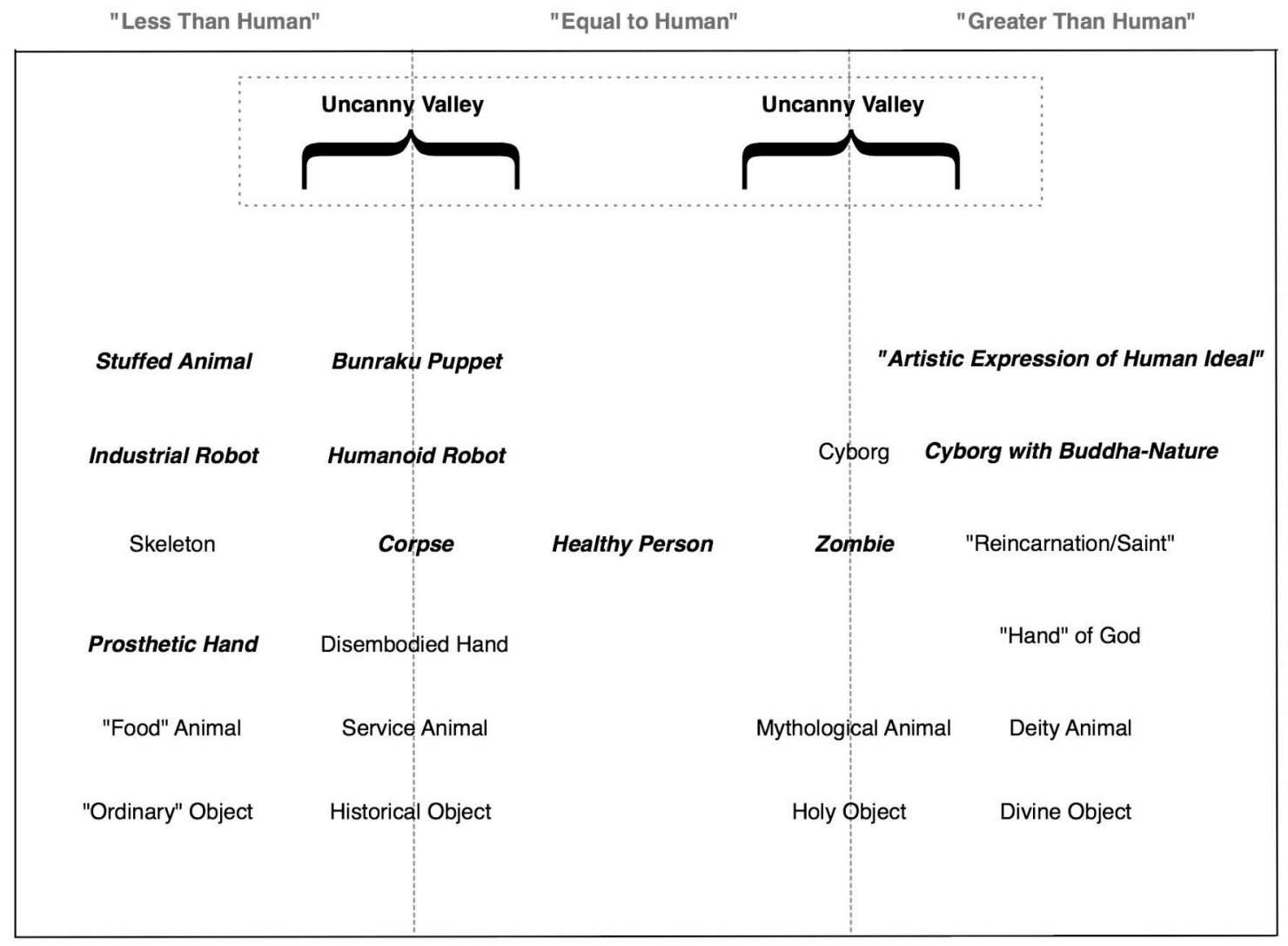

Figure 2: The Ordering of Humanness. This chart overlays the examples (in bold) from Mori's uncanny valley graph onto Luckert's scale of humanness and religious experience. The additional elements (in standard type) were inserted to provide examples for discussion. The elements in the left hand column afford the least potential for religious experience and elements in the right hand column afford the most potential. (Based on Haile, B. and K.W. Luckert, Navajo Coyote Tales : The Curly Tó Aheedliinii Version. 1984, Lincoln: University of Nebraska Press. vi, 146. and Karl F. MacDorman and Takashi Minato's simplified figure from their English translation of Mori, M., Bukimi No Tani [the UnCanny Valley]. Energy, 1970. Volume 7: p. pp.33-35)

Luckert's scale for ordering humanness can be visually represented as a chart with three columns: "less than human", "equal to human", and "greater than human." ${ }^{10}$ In this representation (Figure 2) of Luckert's scale, elements which Mori charted as invoking the uncanny response have been mapped to each side 
of the "equal to human" column. In many cases, these elements could be placed on either side of the "equal to human" column. For example, a zombie could be considered less than human, even though it has superhuman abilities such as life after death. In Blade Runner, Scott frequently shows Roy's disembodied hand without context and these shots are certainly uncanny. Yet his act of forcing a nail into his palm also serves as a means of activating his will to live and references his martyrdom. Roy's hand is both less than and greater than human.

Chew's Eye workshop becomes a factory of the uncanny as Chew picks up disembodied eyes with chopsticks and Leon carefully places eyes on Chew's shoulders and head. Perhaps it is these tenuous boundary areas between the ordering of humanness and the uncanny elements inhabiting them that provoke the sense of danger and discomfort associated with transgression into the "territory of creation." ${ }^{3}$ After all, the replicants only kill those who transgress these boundaries: Holden, who tests for humanness; Chew, who designs eyes; Tyrell, who designs minds; and Sebastian, who engineers genes and uncanny companions for himself. Thus the replicants in Blade Runner rise to the role of punishing the transgressors, a responsibility often taken by deities.

By overlaying the examples from Mori's uncanny valley graph (Figure 1) onto the Ordering of Humanness chart (the elements in bold type in Figure 2), the Cyborg with a Buddha-Nature is transposed from the position on Mori's graph indicating extreme "familiarity" and "human likeness" to the "greater than human" position on Luckert's scale. These correlations locate the second temple of 
cyborgism wherein a mechanical being, 'created' by humankind, rises to the level of "greater than human"10 and thus evokes a religious experience for its creator. ${ }^{a}$ This is The Temple of Cyborg Ascension.

\title{
Less than Human: Cyborg Empathy
}

\begin{abstract}
"An Android," he said, "doesn't care what happens to another android. That's one of the indications we look for."
\end{abstract}

"Then," Miss Luft said, "you must be an android."

That stopped him; he stared at her.

"Because," she continued, "your job is to kill them isn't it?..."

Phillip K. Dick, Do Androids Dream of Electric Sheep?

In depicting Luckert's ordering of humanness (Figure 2), animals enslaved for food production have been placed in the "less than human" category to reflect

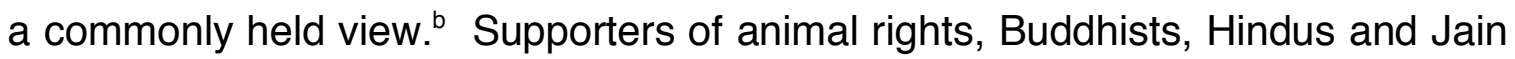
might place all animals in the "equal to" or "greater than" column. A person from the fictional world of Blade Runner might also place non-human animals in the "equal to" or "greater than" columns. In Philip K. Dick's book, Do Androids Dream of Electric Sheep, Deckard contemplates this dilemma of the hunter/hunted dualism: "Empathy, he once had decided, must be limited to herbivores or anyhow omnivores who could depart from a meat diet. Because, ultimately, the empathic gift blurred the boundaries between the hunter and

\footnotetext{
a And perhaps for other beings as well.

b In my personal experience, the eating of animal flesh is not usually considered cannibalism; as such, I am regarding the notion that animals are "less than human" as a commonly held belief.
} 
victim." ${ }^{9}$ These deviations indicate that individuals and cultures will undoubtedly vary in the ordering of elements on Luckert's scale. Dubois confirms that this variation is accounted for in Luckert's theory: "Cultures vary as to how they perceive any given entity and where on this scale they place it. They also vary in the quantity and types of entities they place in each of the three categories..10

In a significant departure from the inspiration for the film, Dick's book ${ }^{9}$, Scott chose to endow replicants with more empathy than his human characters. In Blade Runner, the test designed to measure humanness, Voight-Kampf, attempts to provoke an empathy response through questions about consumption and killing of non-human animals. Unlike the "andys" of Do Androids Dream of Electric Sheep?, the replicants of Blade Runner have empathy for humans, for one another, and perhaps even for animals; Zhora cares for a snake, albeit an 'artificial' one, and Roy handles a dove with care and then releases it just before his death. In his analysis of responses to animal extinctions, Simon A. Cole describes the interactions between 'artificial' animals, replicants and 'real' humans in Blade Runner as "a love triangle, or at least an empathy triangle."11 The ordering of humanness is a chaotic many-sided 'triangle', always in flux, and the meanings of empathy, power and creation are constantly changing.

Karl F. MacDorman has hypothesized that "an uncanny robot elicits an innate fear of death and culturally-supported defenses for coping with death's inevitability."12 Calling on another variety of "culturally-supported defense,"12 Tyrell's replicants, endowed with "more human than human"1 empathy, could 
again function as a "greater than human" 5 element on Luckert's scale and thereby evoke and mediate a religious experience. The cyborg with the Buddha nature would practice Ahimsa and exhibit compassion for all things. This is the emergence of the third temple of cyborgism; The Temple of Cyborg Empathy.

\title{
Marxist Geography v. Technoscience Feminism: The Cyborg Discourse
}

\author{
"Escape from the earth, from the body, from \\ the limits of merely biological evolution is \\ the message and the plot. Man is his own \\ invention; biological evolution fulfills itself in \\ the evolution of technology."13 \\ Donna J. Haraway, Cyborgs to Companion Species
}

If Donna Haraway were asked to place the cyborg on Luckert's scale of humanness, I suspect she would decline to participate. Haraway's cyborg is both a metaphor and a being from a "possible world"14 and although her notion of the cyborg supports the theoretical framework on which the chaotic "territory of creation"3 is founded (as she writes: "cyborg subjectivity will be hybridized, mixed, and plural" ${ }^{14}$ ) she would likely resist my metaphor of the temple and all the resulting implications for cyborg spirituality. 'Dangers of holism,' she might say (this Haraway that is in my head). She might also repeat the warning she issued in a debate with David Harvey at the annual meeting of the Association of American Geographers in 1995:

...some folks pick up the figure of the cyborg and use it in a celebrational mode, and miss the argument that the cyborg issues specifically from the militarized...industrial capitalism...They miss that the cyborg is born as the cyborg enemy....now from that 
particularly unpromising position, what possible kinds of cracks in the system of domination could one imagine beyond a kind of sublimity...wallowing in the sublime of domination...the first and most obvious issue to me is that no world is finally ever closed...looking for the cracks is rule number one. ${ }^{15}$

Oman-Reagan Yes, I understand the danger of celebrating the cyborg as a kind of technophilia without the prophylactic of understanding its militarized origin. But my interest in mapping the "temples of cyborgism" is a process of looking for the cracks. I've watched Blade Runner so many times over the years it has become a mythic narrative for me, the story is part of how I understand my identity now couldn't that be a source for a religious experience? As Tiitsman says: "Fan practice makes more obvious the work which Blade Runner refuses to let us forget. Our spectatorship is a selective subjectivity, an image created in the action of deciding what and how to see..."3 Can't Blade Runner be my origin story? Not in the sense of the mythology of an earlier whole, but in the sense of a story that suggests ways to cope/survive/thrive with a fractured identity.

Haraway "Man births himself through the realization of his intentions in his objects; that is the quest story of masculinist, single-parent, self-birthing. Those objects - those realized intentions - return in the form of the threat of the instrument's surpassing the maker; thus emerges the dialectic of the technophilic, technophobic apocalypse. The myth system is simple and old; cyborg practices are much less simple and much more recent." ${ }^{13}$

Oman-Reagan So, as a queer 'disciple' of Blade Runner, I'm the product of masculinist technoscience and don't have much of a place in the cyborg dialogue? What about the other side, what about Rachel in Blade Runner. She has very little agency without Tyrell or Deckard naming her and telling her what she can do. She's sexualized and victimized throughout the film and only 
survives because she's willing to kill one of her own and can "pass." Is this your ideal feminist cyborg?

Haraway "The replicant Rachel...stands as the image of a cyborg culture's fear, love, and confusion."2

Oman-Reagan If the cyborg experience is confusion, tension, fear - today we're all cyborgs...

In The Condition of Postmodernity, David Harvey considers Blade Runner and Wim Wender's Wings of Desire in a critique of postmodern aesthetics focusing on the postmodern "conceptualization and meanings of time and space." Harvey begins by identifying the replicants as "genetically produced human beings." $\mathrm{He}$ continues: "The replicants are, it should be noted, not mere imitations but totally authentic reproductions, indistinguishable in almost all respects from human beings. They are simulacra rather than robots." 6

Harvey's language here is specific and deserves analysis. He proposes that the replicants are "authentic reproductions." So in this view a reproduction is a copy, but not an "imitation." $\mathrm{He}$ also suggests that a reproduction can be "authentic" and therefore other reproductions can be inauthentic. What is the thing missing from an inauthentic reproduction? Perhaps it is what Walter Benjamin calls the "aura." ${ }^{16}$ If so, what is an aura when applied to a living thing, a sentient being? Is it a soul? And what is an inauthentic reproduction of a sentient being lacking? 
Harvey sums up his ordering of the replicants humanness by noting that the replicants are "simulacra" rather than "robots." 6 This distills questions about his meaning into: What is Harvey's definition of the simulacra? He seems to suggest the simulacra is an authentic reproduction that does not lack anything that is found in the original and yet is still a copy of that original. For another definition, I will look to another Marxist, Henri Lefebvre. ${ }^{c}$ Following a discussion about the difference between present and presence in the book Rhythmanalysis: Time and Everyday Life, Lefebvre defines simulacra as "copies conforming to a standard, parodies of presence."17 Following this definition, Harvey's notion of the replicant as simulacra demands a dialectic, which in turn might suggest binary systems in which one defines the other by opposition. The temples of cyborgism can interface with this dialectic of the simulacra, however, there are no individual replicants or humans; in the temples of cyborgism all beings are products and creators of one another.

In Haraway's manifesto, the cyborg is not an "authentic reproduction," is it an inauthentic reproduction. Rather, Haraway's cyborg is a "hybrid of machine and organism, a creature of social reality as well as a creature of fiction." ${ }^{2}$ Haraway's cyborg is a product of human discourse: "Man births himself through the realization of his intentions in his objects...Man is his own invention." ${ }^{13}$ In the temples of cyborgism this process is played out over and over, just as Tiitsman recounts in her description of the role played by the

\footnotetext{
${ }^{c}$ Thanks to Gregory Donovan of the Environmental Psychology department at the CUNY Graduate Center for directing me to this instance of Lefebvre's definition of simulacra.
} 
concept in the plane of immanence, "We can no longer hold to a sense of creative authorship - creators are thrown into the same turmoil as the created, arising together, momentarily, before plunging back down into the flux." ${ }^{3}$ Mori's spirituality of robotics accounts for this merging when he says that humans and machines are "fused together in an interlocking entity."

It is this fluidity of identity that grants temples of cyborgism access to the supernatural chaos. By straddling boundaries of specification and laying simultaneous claim to multiple identities, cyborgs can mediate supernatural transformative power. This is the final temple of cyborgism; The Temple of Cyborg Discourse.

\section{Conclusion: TechnoGenesis}

"The cyborg would not recognize the Garden of Eden; it is not made of mud and cannot dream of returning to dust."2

Donna J. Haraway, Simians, Cyborgs and Women

As he concludes his critique of Blade Runner, Harvey is troubled by the ambiguity and impermanence of the replicant identity, "The depressing side of the film is precisely that, in the end, the difference between the replicant and the human becomes so unrecognizable that they can indeed fall in love." ${ }^{\text {"6 }}$ After making the case that the Blade Runner replicant is an "authentic reproduction" and not an "imitation," Harvey contradicts himself by bemoaning the invisibility of the distinctions between human and replicant. ${ }^{6}$ 
This contradiction supposes the existence of an ability to see the true identity' of a thing as it moves through various identities; an authenticity ESP. But as Benjamin's Art in the Age of Mechanical Reproduction suggests, a claim to 'authentic reproduction' fails to account for the irreproducibility of that uniqueness on which any claim of 'authenticity' is based: "even the most perfect reproduction...is lacking in one element; its presence in time and space, its unique existence at the place where it happens to be....the whole sphere of authenticity is outside....reproducibility." ${ }^{16}$

Reproduction (both replication and procreation) in the temples of cyborgism is not the creation of simulacra or "parodies of presence,"17 but rather an act of TechnoGenesis. By this I mean (to use Haraway's thoughts on the origin of the word cyborg): "biological evolution fulfills itself in the evolution of technology." ${ }^{13}$ In discussing Alexander Graham Bell's fascination with breeding multi-nippled sheep (certainly an act of TechnoGenesis) Cole writes: "It would seem genetic engineering, reproduction, and technological innovation are all part of a single project of re/production." ${ }^{11}$ What is the product of this "re/production"? ${ }^{11}$ Much more than multi-nippled sheep...

In the final shot of Blade Runner, Deckard and Rachel leave the apartment for the safety of a cyborg sanctuary; 'the wilderness'. We end in the beginning a fracturing of the garden expulsion story; a TechnoGenesis in which the replicant couple have learned who they 'really' are and must now "hide among the trees" as 'Man' walks through the wilderness calling out, "Where are you?"18 


\section{References Cited}

1. Scott, R., et al., Blade Runner - the Directors Cut. 1991, Warner Home Video: Burbank, CA.

2. Haraway, D.J., Simians, Cyborgs, and Women : The Reinvention of Nature. 1991, New York: Routledge. x, 287,11 of plates.

3. Tiitsman, J., If Only You Could See What I've Seen with Your Eyes: Destabilized Spectatorship and Creation's Chaos In "Blade Runner." Cross Currents. 54(1): p. 32-47.

4. Mori, M., On Uncanny Valley, in IEEE-RAS International Conference on Humanoid Robots. 2005: Tsukuba, Japan.

5. Haile, B. and K.W. Luckert, Navajo Coyote Tales : The Curly Tó Aheedlíinii Version. 1984, Lincoln: University of Nebraska Press. vi, 146.

6. Harvey, D., The Condition of Postmodernity : An Enquiry into the Origins of Cultural Change. 1989, Oxford, UK ; Cambridge, Mass.: Blackwell. ix, 378.

7. Mori, M., Bukimi No Tani [the Un-Canny Valley]. Energy, 1970. Volume 7: p. pp.33-35.

8. Mori, M., The Buddha in the Robot. 1st. English ed. 1981, Tokyo: Kosei Pub. Co. 192.

9. Dick, P.K. and R. Zelazny, Do Androids Dream of Electric Sheep? 1st Ballantine Books trade pbk. ed. 1975, New York: Random House. x, 244.

10. DuBois, T.A., Nordic Religions in the Viking Age. 1999, Philadelphia: University of Pennsylvania Press. x, 271.

11. Cole, S.A., Do Androids Pulverize Tiger Bones to Use as Aphrodisiacs? Social Text, 1995(42): p. 173-193. 
12. MacDorman, K.F., Mortality Salience and the Uncanny Valley, in IEEERAS International Conference on Humanoid Robots. 2005: Tsukuba, Japan.

13. Ihde, D. and E. Selinger, Chasing Technoscience : Matrix for Materiality. 2003, Bloomington: Indiana University Press. viii, 249 p.

14. Penley, C., A. Ross, and D. Haraway, Cyborgs at Large: Interview with Donna Haraway. Social Text, 1990(25/26): p. 8-23.

15. Harvey, D. and D. Haraway, Nature, Politics and Possibilities: A Debate and Discussion with David Harvey and Donna Haraway. Environment \& Planning D: Society \& Space. 13(5): p. 507.

16. Mast, G., M. Cohen, and L. Braudy, Film Theory and Criticism : Introductory Readings. 4th ed. 1992, New York: Oxford University Press. xviii, 797.

17. Lefebvre, H., Rhythmanalysis : Space, Time and Everyday Life. 2004, London ; New York: Continuum. xv, 115 p.

18. Jewish Publication Society., [Tanakh] = Tanakh : A New Translation of the Holy Scriptures According to the Traditional Hebrew Text. 1st ed. 1985, Philadelphia: Jewish Publication Society. xxvi, 1624 p. 